\title{
Preliminary Study for Imaging of Therapy Region from Boron Neutron Capture Therapy
}

\author{
Joo-Young Jung ${ }^{\dagger}$, Do-Kun Yoon* ${ }^{\dagger}$, Seong-Min Han $^{\ddagger}$, HongSeok Jang ${ }^{\S}$, Tae Suk Suh*${ }^{\dagger}$ \\ *Department of Biomedical Engineering, The Catholic University of Korea, Seoul, \\ ${ }^{\dagger}$ Research Institute of Biomedical Engineering, The Catholic University of Korea, Seoul, \\ ${ }^{\ddagger}$ Department of Health Science, School of Child and Social Welfare, \\ The Kyungwoon University of Korea, Gumi, ${ }^{\S}$ Department of Radiation Oncology, College of Medicine, \\ The Catholic University of Korea, Seoul St. Mary's Hospital, Seoul, Korea
}

\begin{abstract}
The purpose of this study was to confirm the feasibility of imaging of therapy region from the boron neutron capture therapy (BNCT) using the measurement of the prompt gamma ray depending on the neutron flux. Through the Monte Carlo simulation, we performed the verification of physical phenomena from the BNCT; (1) the effects of neutron according to the existence of boron uptake region (BUR), (2) the internal and external measurement of prompt gamma ray dose, (3) the energy spectrum by the prompt gamma ray. All simulation results were deducted using the Monte Carlo n-particle extended (MCNPX, Ver.2.6.0, Los Alamos National Laboratory, Los Alamos, NM, USA) simulation tool. The virtual water phantom, thermal neutron source, and BURs were simulated using the MCNPX. The energy of the thermal neutron source was defined as below $1 \mathrm{eV}$ with 2,000,000 $\mathrm{n} / \mathrm{sec}$ flux. The prompt gamma ray was measured with the direction of beam path in the water phantom. The detector material was defined as the lutetium-yttrium oxyorthosilicate (Lu0,6Y1,4Si0,5:Ce; LYSO) scintillator with lead shielding for the collimation. The BUR's height was $5 \mathrm{~cm}$ with the 28 frames (bin: $0.18 \mathrm{~cm}$ ) for the dose calculation. The neutron flux was decreased dramatically at the shallow region of BUR. In addition, the dose of prompt gamma ray was confirmed at the $9 \mathrm{~cm}$ depth from water surface, which is the start point of the BUR. In the energy spectrum, the prompt gamma ray peak of the $478 \mathrm{keV}$ was appeared clearly with full width at half maximum (FWHM) of the $41 \mathrm{keV}$ (energy resolution: 8.5\%). In conclusion, the therapy region can be monitored by the gamma camera and single photon emission computed tomography (SPECT) using the measurement of the prompt gamma ray during the BNCT.
\end{abstract}

Key Words: BNCT, Neutron flux, Prompt gamma ray, Monte Carlo, MCNPX

\section{서 론}

붕소 중성자 포획 치료는 종양에 붕소가 표지된 화합물 을 집적시키고 중성자를 조사하여 정상 조직의 손상을 최

This research was supported by the Leading Foreign Research Institute Recruitment Program through the National Research Foundation of Korea (NRF) funded by the Ministry of Science, Information and Communication Technologies (ICT)\&Future Planning (MSIP) (Grant No. 2009-00420) and the Radiation Technology R\&D program (Grant No. 2013M2A2A7043498), Republic of Korea.

Received 7 July 2014, Revised 31 July 2014, Accepted 7 August 2014 Correspondence: Tae Suk Suh (suhsanta@catholic.ac.kr) Tel: 82-2-2258-7232, Fax: 82-2-2258-7506

(C) This is an Open-Access article distributed under the terms of the Creative Commons Attribution Non-Commercial License (http://creativecommons.org/licenses/by-nc/3.0) which permits unrestricted non-commercial use, distribution, and reproduction in any medium, provided the original work is properly cited.
소화하고, 종양 조직의 피해를 극대화하는 치료 방법이다. ${ }^{1-3)}$ 이 때 사용하는 붕소 표지 화합물(boronated compound)은 주로 안정화 상태인 붕소(원자번호: 10)와 종양 조직에 친 화력을 가지는 보로캅테이트 나트륨(borocaptate sodium, ${ }^{10} \mathrm{~B}-$ $\mathrm{BSH}$ ) 또는 페닐알라닌(paraboronophenylalanine, $\left.{ }^{10} \mathrm{~B}-\mathrm{BPA}\right)$ 을 주로 사용한다. ${ }^{45)}$ 이것은 정상 조직 이외에 종양 조직에서 혈뇌장벽(blood-brain barrier, $\mathrm{BBB}$ )의 특성이 더욱 높아져 종 양 조직 안에서, 붕소와 중성자의 $\mathrm{n}, \alpha$ 반응을 유도할 수 있다. 표지 화합물을 집적시킨 후 $1 \mathrm{eV}$ 이하의 열 중성자 (thermal neutron)를 조사하게 되면 종양에 집적된 붕소는 중성자를 포획하여 여기되고, 리튬 이온과 알파 입자 그리 고 즉발 감마선을 방출하면서 안정화 상태로 돌아간다.) 여기서 나오는 알파 입자가 종양을 치료하는 입자가 되며 에너지는 $0.84 \mathrm{MeV}$ 정도의 생물학적 영향이 높은 강한 에 
Joo-Young Jung, et al : Preliminary Study for Imaging of Therapy Region from Boron Neutron Capture Therapy

너지를 방출한다. ${ }^{7)}$ 그 알파 입자는 비정이 $0.3 \sim 0.9 \mu \mathrm{m}$ 이 므로, 붕소가 집적된 종양 조직, 종양 세포 반지름 수준에 서만 반응이 일어나 국소적으로 치료 효율을 증대시킬 수 있다. ${ }^{8)}$ 붕소 중성자 포획 치료는 주로 뇌종양 치료에 많이 사용되고 있는데, 심부에 위치한 종양일 경우 열중성자(thermal neutron) 이외에 열외중성자(epithermal neutron)를 사용 하는 시도가 많이 이루어지고 있다.,10)

종양 조직에서의 ${ }^{10} \mathrm{~B}(\mathrm{n}, \alpha)^{7} \mathrm{Li}$ 반응에 따라 반응 지점에서 특정 에너지를 가진 즉발 감마선이 방출되는데, 이것을 감 마 카메라(Gamma camera) 또는 단일 광자 방출 단층 촬영 (single photon emission computed tomography, SPECT)로 신호를 획득하게 되면 치료 영역에 대한 영상화 가능성이 있다. ${ }^{11,12)}$

따라서 본 연구의 목적은 집적된 붕소 영역에서 중성자 선속의 변화와 그에 따른 방출된 즉발 감마선량을 측정하 여 치료 영역에 대한 영상화의 가능성을 전산 모사를 통하 여 확인하고자 함이다.

\section{재료 및 방법}

\section{1. 중성자 선속 변화 계측}

붕소 중성자 포획 치료에서의 중성자 선속에 따른 즉발 감마선의 영향을 보기 위하여 몇 가지 전산 모사가 시행되 었다. 우선 첫 번째로 붕소의 존재에 따른 중성자의 영향을 평가하기 위하여 물 팬텀을 전산 모사에 입력하였다. 물 팬 텀 $\left(28 \times 28 \times 28 \mathrm{~cm}^{3}\right)$ 은 실제 물과 동일한 원자 정보와 물질 정보를 기반으로 설정하였다. 여기에 중성자 발생기(D-T generator)로부터 나오는 열 중성자 빔 $(<1 \mathrm{eV})$ 을 물 팬텀을 향하여 입사시키는 구조로 전산 모사를 시행하였다. 여기 서 열중성자 소스는 물 팬텀 표면으로부터 $20 \mathrm{~cm}$ 의 거리를 가지고 있으며 선속은 $2,000,000 \mathrm{n} / \mathrm{sec}$ 의 선속으로 물 팬텀 에 입사되도록 하였다. 또한 붕소에 (밀도: $2.08 \mathrm{~g} / \mathrm{cm}^{3}$ )의한 영향 평가의 잣대로 물 팬텀 중간에 표면으로부터 $9 \mathrm{~cm}$ 깊 이에 $5 \mathrm{~cm}$ 두께의 붕소 영역을 포함시켜 비교군 전산모사 프로파일을 작성하였다. 작성된 전산 모사 프로파일을 토 대로 전산 모사를 시행하여 붕소가 없는 물 팬텀에서의 중 성자의 선속 변화와 붕소가 물 팬텀 중간에 포함되어 있을 때의 선속의 변화, 붕소 영역 내에서의 중성자의 선속 변화 에 대한 전산 모사 결과를 도출하였다. 선속에 대한 계산은 물 팬텀과 붕소 영역을 일정 간격 $(1 \mathrm{~cm})$ 으로 분할하여 각 영역을 통과하는 선속을 Monte Carlo n-particle extended (MCNPX, Ver.2.6.0, Los Alamos National Laboratory, Los Alamos, NM, USA) 내에 선속 Tally인 F4-tally를 지정하여
각 Tally 값을 추출, 선속 프로파일을 작성하였다. ${ }^{13)}$

\section{2. 깊이에 따른 내·외부 즉발 감마선 계측}

앞서 시행된 전산 모사는 중성자의 선속 변화를 관찰한 것이고, 두 번째 전산 모사로 본 논문에서 확인하고자 하는 즉발 감마선의 선량을 외부와 내부에서 각각 계측한 결과 를 도출하고자 하였다. 물 팬텀 외부에서 감마선 검출기를 이용하여 팬텀 밖으로 투과하여 방출되는 감마선을 팬텀 내 셀이 분할된 방향의 수직된 방향으로 나오는 즉발 감마 선을 계측하여 각 셀마다 방출되는 즉발 감마선의 단위 선 량을 계측하는 것이 외부적 검출이다. 또한 외부로 투과하 지 못하고 팬텀 내에서 흡수된 즉발 감마선량을 역시 각 셀 별로 계측한 것이 내부적 검출이다. 이는 물 자체로부터 흡수 선량을 검출하는 것이므로 실제적인 실험으로 검출값을 획득하는 것은 불가능하다. 모든 기하학적 정보(geometry)는 동일하게 설정하였고 외부에서 즉발 감마선을 계측하기 위 하여 납으로 둘러싸인 lutetium-yttrium oxyorthosilicate (Lu0, $6 \mathrm{Y} 1,4 \mathrm{Si} 0,5: \mathrm{Ce}$; LYSO, density $=7.3 \mathrm{~g} / \mathrm{cm}^{3}$ ) 섬광체 검출기를 이용하여 즉발 감마선의 선량을 계측하였다. ${ }^{14)}$ 납 차폐체 는 물 팬텀과 수직 방향을 향하고 있는데, 분할된 각 셀 마 다 수직으로 나오는 즉발 감마선을 계측하기 위함이다. 납 차폐체의 끝 부분과 물 팬텀 수직면의 표면과 $50 \mathrm{~cm}$ 의 거 리를 가지고 있고 납 차폐체의 두께는 $3 \mathrm{~cm}$, 높이는 $20 \mathrm{~cm}$ 로 설정하였고 섬광체는 납 차폐체 속 $10 \mathrm{~cm}$ 깊이에 위치 하여 $1.6 \mathrm{~cm}$ 지름과 $10 \mathrm{~cm}$ 의 두께를 가지고 있다. 이 검출 기가 물 팬텀의 끝 단부터 다른 끝 단에 이르기까지 수직 방향으로 이동하여 중성자와 물 팬텀을 지나가면서 발생시 키는 즉발 감마선을 계측하도록 하였다.

전산 모사 상에서 섬광체에 대해 흡수 선량 Tally인 F6tally를 설정하여 즉발 감마선에 대한 계측을 시도하였다. 반면에 내부적 감마선에 대한 계측은 앞서 분할된 물 팬텀 에서 각 셀에 대하여 광자에 대한 흡수 선량을 설정하여 중성자가 물 팬텀과 붕소 영역을 통과하며 발생시키는 즉 발 감마선의 선량을 계측하도록 하였다.

\section{3. 즉발 감마선의 에너지 스펙트럼}

마지막 전산 모사로 즉발 감마선에 대한 에너지 스펙트 럼을 계측하였다. 이 역시 기본적으로 동일한 geometry의 물 팬텀에 붕소 영역을 포함시키고 열중성자를 입사 시켜 붕소 영역에서 발생되는 감마선을 에너지 별로 카운트하였 는데, 여기서 원통형 섬광체는 $50 \mathrm{~cm}$ 의 내부 반지름과 10 $\mathrm{cm}$ 의 두께를 가지고 팬텀 외부를 감싸고 있다. 섬광체는 
동일한 LYSO로 설정하였고 전산 모사 상에 섬광체에 대한 에너지 별 광자의 누적 계수 Tally인 F8-tally를 설정하여 스 펙트럼을 계측, 에너지 bin 값은 $10 \mathrm{keV}$ 로 설정하였고 Gaussian energy broadening (GEB) 설정은 다른 논문에서 실 험을 통하여 계측된 LYSO의 $511 \mathrm{keV}, 662 \mathrm{keV}$ 에서의 반 치폭을 참조하여 $\mathrm{GEB}$ 값을 설정하여 스펙트럼을 얻을 수 있었다. ${ }^{15)}$ 이론상으로 붕소에 중성자가 포획될 때 알파입 자와 리튬 이온이 방출되면서 $478 \mathrm{keV}$ 의 즉발 감마선이 방 출되는데 이를 계측한 감마선 에너지 스펙트럼에서 관찰할 수 있다.

\section{결 과}

\section{1. 중성자 선속 프로파일}

첫 번째로 시행한 전산 모사의 경우 물 팬텀 내에 입사되 는 중성자의 선속을 확인하고자 하였다. 여기서 변수로 붕

a

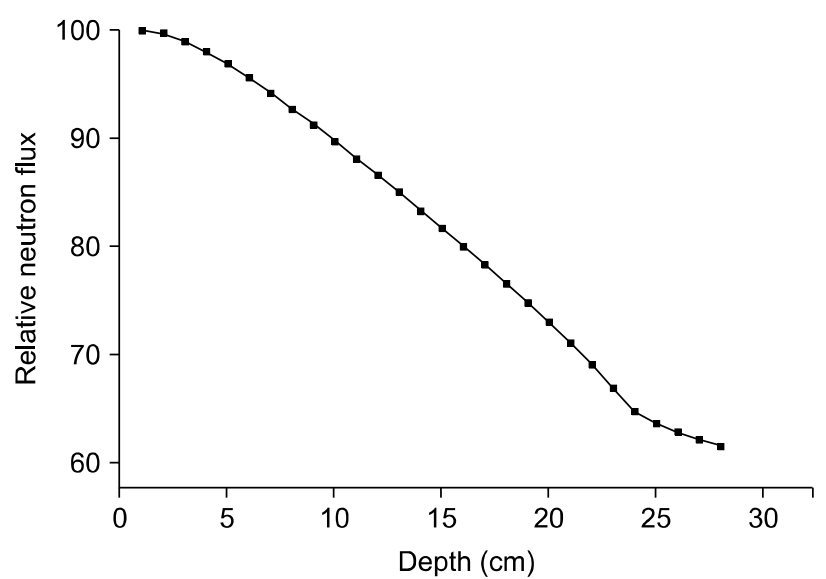

C

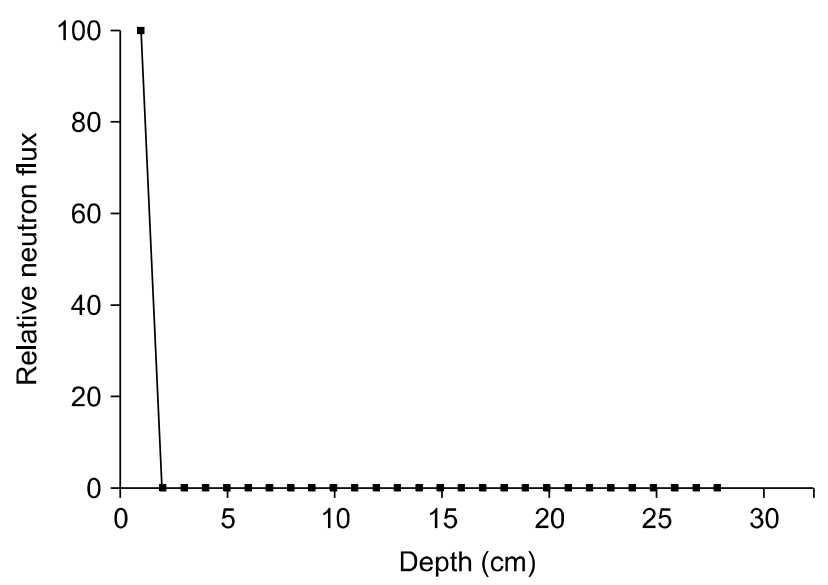

소 영역이 존재할 때와 존재하지 않을 때, 붕소 영역 내에 서의 중성자 선속을 계측한 결과, Fig. 1과 같은 결과가 도 출되었다. 우선 Fig. 1(a)의 경우 물 팬텀 내에 붕소 영역 없 이 물만 존재할 때의 중성자 선속의 변화를 보여준다. 또한 Fig. 1(b)는 붕소 영역이 존재할 때의 중성자 선속을 보여주 는 그래프 인데, 앞서 거론된 $9 \mathrm{~cm}$ 깊이에서의 붕소 영역 에서 중성자의 선속이 급격히 감소되는 모습을 보여주는데 물만 존재할 때의 중성자 선속과 비교되는 모습을 보여주 고 있다. Fig. 1(c)는 붕소 영역 내(5 cm 두께) 있을 때 각 분 할 지점에 대한 중성자 선속의 변화를 보여준다. $5 \mathrm{~cm}$ 에 대한 28 분할로서 대략 $0.18 \mathrm{~cm}$ 의 bin을 가지고 계측된 결 과인데 붕소 영역의 얕은 깊이에서 급격하게 저하되는 모 습을 보여주고 있다.

\section{2. 즉발 감마선 프로파일}

두 번째 전산 모사로 즉발 감마선에 대한 외부 계측과

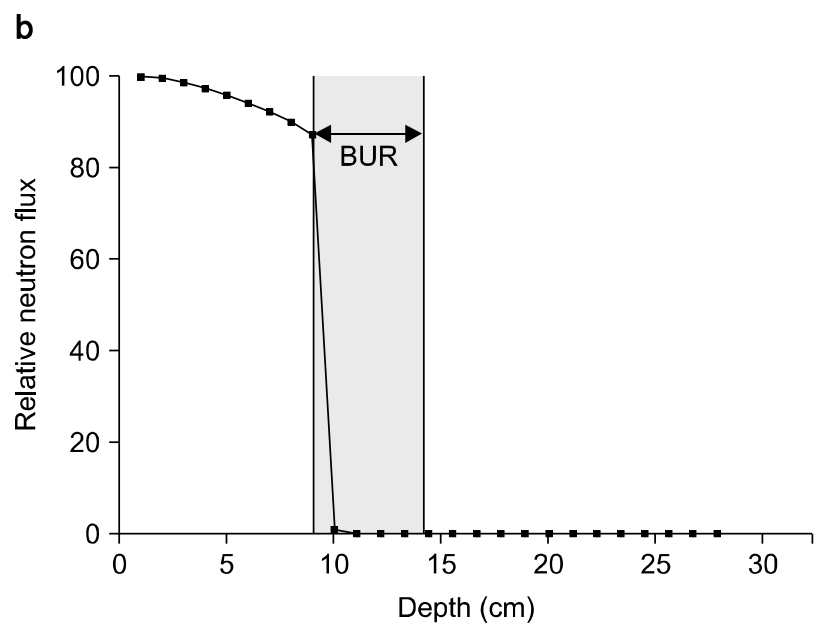

Fig. 1. Change of the neutron flux depending on the depth of the phantom. (a) The neutron flux according to the depth from the water phantom without boron uptake region (BUR), (b) The neutron flux according to the depth from the water phantom with boron uptake region (BUR), (c) the change of the neutron flux from the BUR. 
a

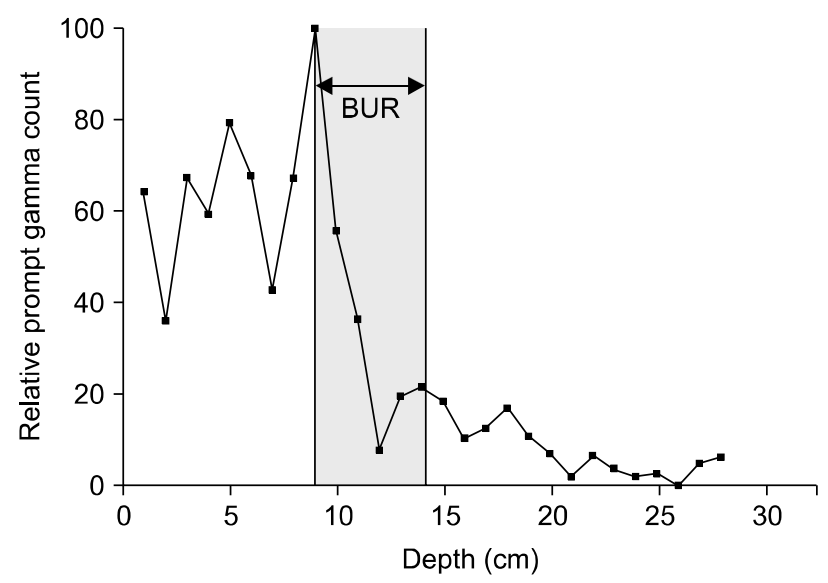

b

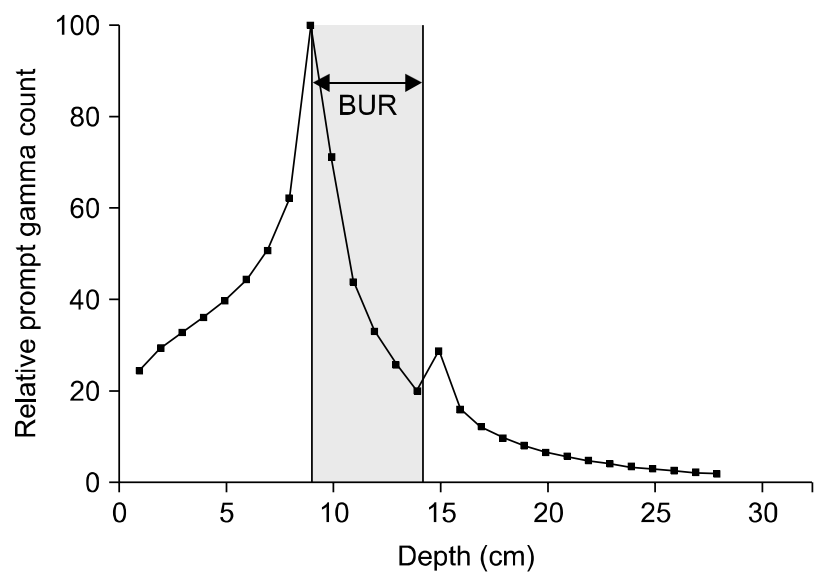

Fig. 2. Percentage depth dose of the prompt gamma ray from the phantom; (a) the external detection using the detector, (b) in-vivo dosimetry using the simulation.

내부 계측을 비교한 것인데, 결과는 Fig. 2에서와 같이 도 출되었다. Fig. 2(a)에서 외부에 위치한 검출기로 물 팬텀에 수직 방향으로 이동되면서 계측한 즉발 감마선의 계측 결 과를 보여주는데 붕소 영역이 시작되는 지점인 $9 \mathrm{~cm}$ 깊이 에서 감마선 레벨이 최고치가 되는 것을 볼 수 있다. 또한 Fig. 2(b)에서 물 팬텀 내부에서 중성자가 지나가면서 발생 시키는 감마선의 선량을 보여주는 그래프인데 이 결과에서 도 역시 $9 \mathrm{~cm}$ 깊이에서부터 감마선 레벨이 최고점에 이르 는 것을 볼 수 있다.

\section{3. 에너지 스펙트럼}

마지막 전산 모사로 물 팬텀 내에 붕소 영역이 있고 중 성자와 반응할 때 나오는 감마선 스펙트럼을 계측한 결과 가 Fig. 3에서 보여지고 있다. 앞서 거론된 이론에 따라 478 $\mathrm{keV}$ 지점에서 정확한 즉발 감마선 피크가 관찰되는 것을 확인하였다. $478 \mathrm{keV}$ 의 즉발 감마선 피크는 $41 \mathrm{keV}$ 의 반치 폭으로 에너지 분해능 값은 $8.5 \%$ 로 측정되었다.

\section{고찰 및 결론}

본 연구에서는 붕소 중성자 포획 치료 시 발생되는 즉발 감마선의 계측으로 치료가 행해지는 부위를 영상화할 수 있는 논리를 증명하기 위하여 몇 가지의 전산 모사가 시행 되었다.

우선 첫 번째로 시행된 중성자 선속에 관한 전산 모사에 서 붕소 영역이 없는 물 팬텀 내부를 중성자가 통과할 때

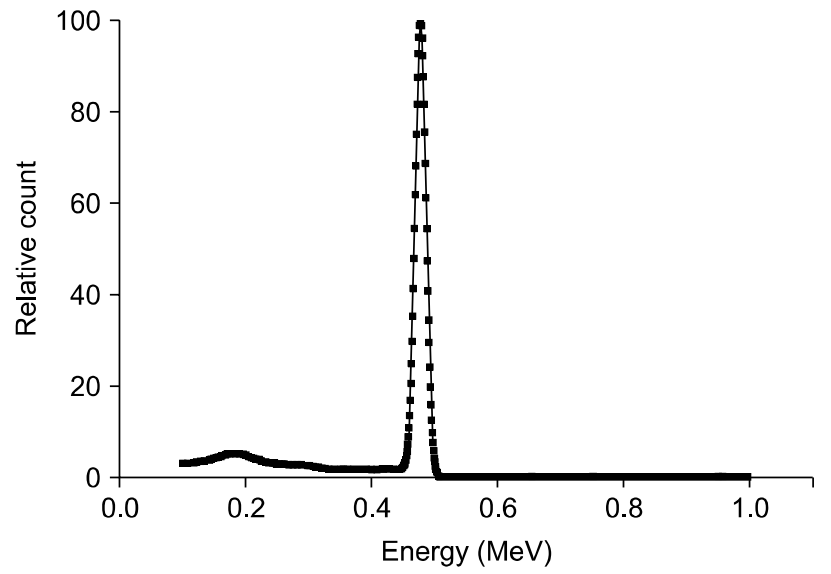

Fig. 3. Energy spectrum including the prompt gamma ray peak of the $478 \mathrm{keV}$ with the full width at half maximum of the 41 $\mathrm{keV}$ (energy resolution: 8.5\%).

선속의 변화와 붕소 영역이 존재할 때의 중성자 선속의 변 화를 결과로서 확인하였다. 물 내부만을 통과할 때에는 차 츰 감소되는 중성자의 선속을 볼 수 있지만 붕소가 존재할 시 중성자의 선속이 $1 \mathrm{~cm}$ 이내에서 $85 \%$ 이상 줄어드는 모 습을 볼 수 있었다. 이 결과는 두 가지의 원인으로부터 기 인하는데, 하나는 기본적인 붕소의 밀도에 의한 차폐 효과 이고 또 하나는 붕소에 의한 포획 반응으로 분할된 셀을 통과하는 선속이 급작스럽게 감소된 양상을 보여준다. 중 성자가 붕소 영역에서 에너지를 잃기만 하고 포획 반응이 일어나지 않을 경우도 선속의 측정이 줄어드는 요인으로 작용한다. 만약 차폐에 의한 선속의 감소라면 $9 \mathrm{~cm}$ 깊이에 
서의 즉발 감마선의 발생이 관찰되지 않을 것이다. 또한 붕 소 내부 영역에서도 붕소 영역을 투과한 선속이 $0.53 \mathrm{~cm}$ 깊이 내에서 중성자 선속의 $99 \%$ 가 감소되는 모습을 볼 수 있는데, 이 역시 상기의 두 가지 이유로 인한 급격한 감소 를 야기시켰다고 할 수 있다. 실제 종양에서는 전산 모사상 에서 설정된 밀도보다 $1 \mathrm{~g} / \mathrm{cm}^{3}$ 가량 밀도가 낮아지기 때문 에 실제 임상에서는 이 보다 더 깊은 위치까지 중성자 선 속이 영향을 미칠 수 있다고 판단된다.

두 번째 전산 모사의 결과는 즉발 감마선의 외부적과 내 부적 계측을 보여주는 것인데, 외부적 계측 결과에서 붕소 가 시작되는 $9 \mathrm{~cm}$ 깊이에서부터 감마선 계측이 최대치에 이르는 것을 보여주고 있으며 $10 \mathrm{~cm}$ 거리에서(붕소 영역 깊이 $1 \mathrm{~cm}) 45 \%$ 의 선량 감축과 $14 \mathrm{~cm}$ 거리, 즉 붕소 영역 깊이 $5 \mathrm{~cm}$ 지점에서는 $79 \%$ 의 선량 감소를 보여주고 있다. 또한 내부적 계측에서도 마찬가지로 붕소 영역이 시작되는 $9 \mathrm{~cm}$ 지점에서 최대치의 선량을 주고 $10 \mathrm{~cm}$ 깊이에서 $29 \%, 14 \mathrm{~cm}$ 깊이에서 $80 \%$ 의 선량 감소를 보여주고 있다. 이는 외부적, 내부적 계측 모두 같은 양상을 보여주며 붕소 시작 부분과 붕소 영역 내에 선속이 급격히 감소되는 부분 과 거의 정확하게 일치되는 모습을 보여준다. 즉 중성자와 붕소의 포획 반응이 활발히 일어났음을 보여주는 결과이 다. 계측된 선량의 최대치 이외의 부분은 Fig. 2 와 같이 외 부적 검출과 내부적 검출에서 다른 경향성을 보여주는데, 이는 검출되는 거리와 다른 매질의 특성상 일치되지 않는 것을 보여주고 있다.

마지막 전산 모사에서는 감마선 에너지 스펙트럼을 통하 여 감마선의 에너지 별 계수 정도를 그래프화 하였는데, 앞 서 거론된 이론대로 $478 \mathrm{keV}$ 의 즉발 감마선 피크가 정확히 계측된 것을 볼 수 있었다. 스펙트럼상에서는 별도로 계측 되는 백그라운드에 비하여 비교적 높은 계수율을 보이고 있으며 이를 토대로 에너지 윈도우를 설정, Gamma camera 또는 SPECT에서 해당 피크만을 선별하여 집속하게 되면 치료 부위가 핵의학 영상처럼 재구성될 수 있다는 것이다. 만약 이것을 토대로 영상이 재구성된다면 붕소 중성자 포 획 치료 시 치료 중에 치료가 되는 부위에 대한 모니터링 이 가능해진다. 이로써 좀 더 효율적인 치료와 진단이 가능 해지며 추가적인 검사를 줄일 수 있는 효과를 가져올 수 있다.

본 연구에서는 붕소 중성자 포획 치료 시 발생되는 즉발 감마선의 계측을 통하여 중성자 선속과의 관계를 규명하 고, 후에 $478 \mathrm{keV}$ 에 대한 단일 광자를 핵의학 기기로 영상 화 할 수 있을지에 대한 여부를 전산 모사로써 알아보았다.
붕소와 중성자의 포획 반응은 높은 반응 단면적을 통하여 이루어지며 그에 따라 발생되는 알파 입자는 비정이 짧아 포획 반응이 일어난 지점에서 치료가 이루어지며, 또한 포 획 지점에서 발생되는 즉발 감마선은 충분한 계수율을 가 지고 있고 핵의학 장비로 영상화 할 수 있는 충분한 가능 성이 제기되었다. 향후 진행될 연구로는 확인된 가능성을 토대로 붕소 중성자 포획 치료 시 발생되는 $478 \mathrm{keV}$ 에 대 한 단일 광자 피크로 SPECT에 대한 영상을 재구성 해보는 연구가 진행될 예정이다.

\section{Referenes}

1. Ono K, Kinashi Y, Masunaga S, Suzuki M, Takagaki M: Electroporation increases the effect of borocaptate (10B-BSH) in neutron capture therapy. Int. J. Radiat. Oncol. Biol. Phys. 42:823-826 (1998)

2. Barth RF, Soloway AH, Goodman JH, Gahbauer RA, Gupta N, Blue TE, et al: Boron neutron capture therapy of brain tumors: an emerging therapeutic modality. Neurosurgery 44:433-503 (1999)

3. Barth RF, Grecula JC, Yang W, Rotaru JH, Nawrocky M, Gupta N, et al: Combination of boron neutron capture therapy and external beam radiotherapy for brain tumors. Int. J. Radiat. Oncol. Biol. Phys. 58:267-277 (2004)

4. Sherlock Huang LC, Hsieh WY, Chen JY, et al: Drug delivery system design and development for boron neutron capture therapy on cancer treatment. Appl. Radiat. Isot. 88:89-93 (2014)

5. Yokoyama K, Miyatake S, Kajimoto $Y$, et al: Pharmacokinetic study of BSH and BPA in simultaneous use for BNCT. J. Neurooncol. 78:227-232 (2006)

6. Munck af Rosenschöld PM, Verbakel WFAR, Ceberg $\mathrm{CP}$, et al: Toward clinical application of prompt gamma spectroscopy for in vivo monitoring of boron uptake in boron neutron capture therapy. Med. Phys. 28:787-795 (2001)

7. Kinashi $Y$, Masunaga S, Nagata K, et al: A bystander effect observed in boron neutron capture therapy: a study of the induction of mutations in the HPRT locus. Int. J. Radiat. Oncol. Biol. Phys. 68:508-514 (2007)

8. Kankaanranta L, Seppala $T$, Koivunoro $H$, et al: Boron neutron capture therapy in the treatment of locally recurred head-and-neck cancer: final analysis of a phase $1 / /$ l trial. Int. J. Radiat. Oncol. Biol. Phys. 82:e67-e75 (2012)

9. Culbertson, C. N., Green, S., Mason, A. J., Picton, D., Baugh, G., Hugtenburg, R. P., Nelson, J. M.: In-phantom characterisation studies at the Birmingham Accelerator-Generated eplthermal Neutron Source (BAGINS) BNCT facility. Appl. Radiat. Isot. 61:733-738 (2004)

10. Moss, R. L., Stecher-Rasmussen, F., Ravensberg, K., Constantine, G., Watkins, P.: Design, construction and installation of an epithermal neutron beam for BNCT at the high 
Joo-Young Jung, et al : Preliminary Study for Imaging of Therapy Region from Boron Neutron Capture Therapy

flux reactor Petten. Progress in Neutron Capture Therapy for Cancer, Springer US, 63-66 (1992)

11. Bartoli, A., Belcari, N., Del Guerra, A., and Fabbri, S.: Simultaneous PET/SPECT imaging with the small animal scanner YAP-(S) PET. IEEE Nuclear Science Symposium Conference Record, 2007 NSS 5:3408-3413 (2007)

12. Yao R, Deng X, Beaudoin J-F, Ma T, Cadorette J, Cao $Z$, et al: Initial Evaluation of LabPET/SPECT Dual Modality Animal Imaging System. IEEE Transactions on Nuclear Science, 60:76-81 (2013)

13. Giuliano, D. R.: Neutron Flux Measurements and Calculations in the Gamma Irradiation Facility Using MCNPX. Doctoral dissertation, University of Cincinnati. (2010)

14. Pidol L, Kahn-Harari A, Viana B, Virey E, Ferrand B, Dorenbos $P$, et al: High efficiency of lutetium silicate scintillators, Ce-doped LPS and LYSO crystals. IEEE Nuclear Science Symposium Conference Record, 2:886-890 (2003)

15. Chewpraditkul, W., Swiderski, L., Moszynski, M., Szczesniak, T., Syntfeld-Kazuch, A., Wanarak, C., \& Limsuwan, P: Scintillation properties of LuAG: Ce, YAG: Ce and LYSO: Ce crystals for gamma-ray detection. Nuclear Science, IEEE Transactions on, 56:3800-3805 (2009)

\section{붕소 중성자 포획 치료에서 치료 영역 영상화를 위한 예비 연구}

*가톨릭대학교 의과대학 의공학교실, ${ }^{\dagger}$ 가톨릭대학교 의과대학 생체의공학연구소,
${ }^{{ }^{2}}$ 경운대학교 사회과학대학 아동사회복지학부, ${ }^{\circledR}$ 서울성모병원 방사선종양학과

$$
\text { 정주영 } *^{\dagger} \cdot \text { 윤도군 } *^{\dagger} \cdot \text { 한성민 }^{\dagger} \cdot \text { 장홍석 }^{\S} \text { 서태석* }{ }^{\dagger}
$$

본 연구의 목적은 붕소 중성자 포획 치료 시 집적된 붕소 영역에서 중성자 선속의 변화와 그에 따른 방출된 즉발 감마선 의 검출 시뮬레이션을 통하여 치료 영역에 대한 영상화의 가능성을 확인하고자 함이다. 전산 모사를 통하여 (1) 붕소 유 무에 따른 중성자의 영향, (2) 내부와 외부에서의 즉발 감마선량 검출, (3) 즉발 감마선에 대한 에너지 스펙트럼 검출을 수행하였다. 모든 전산 모사는 Monte Carlo n-particle extended (MCNPX, Ver.2.6.0, Los Alamos National Laboratory, Los Alamos, NM, USA)를 이용하여 가상의 물 팬텀과 열중성자(thermal neutron) 소스, 붕소 영역을 지정하였다. 열중성자의 에너지는 $1 \mathrm{eV}$ 이하의 에너지였으며 선속은 $2,000,000 \mathrm{n} / \mathrm{sec}$.로 설정하였다. 이 때, 발생된 즉발 감마선의 검출은 물 팬텀 과 수직 방향으로 위치시키고 납으로 둘러싸인 lutetium-yttrium oxyorthosilicate (Lu0,6Y1,4Si0,5:Ce; LYSO) 섬광체 검출기 를 이용하였다. 붕소가 존재하는 영역인 $5 \mathrm{~cm}$ 깊이에서의 28 분할로서 대략 $0.18 \mathrm{~cm}$ 의 bin을 도출하여 붕소 영역의 얕은 깊이에서부터 급격하게 저하되는 것을 확인하였다. 또한 붕소 영역이 시작되는 지점인 $9 \mathrm{~cm}$ 깊이에서 감마선의 피크 레 벨을 확인하였다. 그리고 $478 \mathrm{keV}$ 지점에서 정확한 즉발 감마선 피크가 관찰되는 것을 확인하였다. $478 \mathrm{keV}$ 의 즉발 감마 선 피크는 $41 \mathrm{keV}$ 의 반치폭으로 에너지 분해능 값은 $8.5 \%$ 로 측정되었다. 결론적으로 붕소 중성자 포획 치료 시 발생되 는 즉발 감마선의 계측으로 치료가 행해지는 부위를 감마 카메라 또는 단일 광자 방출 단층 촬영 기기에서 영상화할 수 있는 가능성을 확인하였다.

중심단어: 붕소 중성자 포획 치료, 중성자 선속, 즉발 감마선, 몬테칼로, MCNPX 